Diánoia, vol. 35, no. 35, 1989

\title{
ÉTICA SIN RAÍCES
}

ALBERTO VARGAS

UNIVERSIDAD AUTÓNOMA METROPOLITANA - IzTAPALAPA

La grandeur d'un homme n'est pas seulement fonction de ses facultés, de son intelligence, de ses dons quels qu'ils soient: Elle est faite aussi de circonstances qui l'ont élu pour leur servir de support. Un homme est grand s'il a un grand destin; mais cette grandeur est de l'ordre des grandeurs visibles, mesurables. Elle est la magnificence vue du dehors. Misèrable peut-être, vue du dedans, elle est alors poćtique...

Jean Genet

Quisiera ocuparme en este trabajo de una de las dos formas que toma el pensamiento de Wittgenstein a propósito de la ética. Creo, en efecto, que hay dos vertientes en este pensamiento, dos éticas de Wittgenstein. En la primera de ellas, el valor ético se concibe como absoluto; en la segunda, el valor depende de condiciones históricas y culturales. Baso mi exposición en el libro que con el título Observaciones ha sido publicado en traducción al castellano por Elsa Cecilia Frost. ${ }^{1}$ Sirven de telón de fondo las 19 últimas páginas del Diario filosfifico (1914-1916) y la "Conferencia sobre ética". Me ocupo primero del problema general de la ética en el pensamiento de Wittgenstein, esbozo luego la separación de las dos éticas y, finalmente, intento caracterizar la segunda de ellas.

La preocupación que abre el dominio ético es la preocupación acerca de la vida humana: la manera correcta de vivir, la pregunta por aquello que es realmente importante o valioso, aquello que da valor a la existencia humana. A esta preocupación la llama Wittgenstcin en la "Conferencia" el problema del sentido de la vida. En tanto consideremos a la vida como un problema, dos preguntas aparecen de inmediato: (1) iqué significa que haya aquí un problema? o, planteado de otro modo, ¿qué sería que la vida no apareciese como algo problemático? (2) icuál es la solución a este problema?

En lo que respecta a la primera pregunta, me parece que la respuesta de Wittgenstein es doble. Por un lado, observa que el problema ético y, más generalmente, el problema del valor es algo que tiene su origen en la conciencia

1 Ludwig Wittgenstein, Obserracionar, trad. de Elsa Cecilia Frost, Siglo XXI, México, 1981. 
de la unicidad de la vida, es decir, toda valoración toma necesariamente como punto de partida la perspectiva del individuo:

Sólo de la conciencia de la unicidad de mi vida surgen religión —ciencia-y arte. (Diario filosofico, 1.8.16.)

Y con ellas surgen las valoraciones y el pensamiento sobre la valoración. El problema de la vida, de su sentido, de su valor, emerge como una manifestación de esta conciencia de la unicidad de la vida. Por otro lado, es por la duda acerca de lo que uno hace, acerca de la manera en que uno vive su vida y, por consiguiente, por el hecho de una cierta insatisfacción, por lo que la vida se torna problemática: la vida de uno no parece ajustarse a la forma (a un cierto ideal, diríamos) de la vida. La duda, la insatisfacción y la tristeza actúan como acicates para generar la pregunta por el sentido de la vida. Por ambas vías aparece la inquietud acerca de lo valioso y lo bueno. Me parece que lo importante que hay que señalar aquí es la manera radicalmente distinta en que surge el problema. Hay cierta ambigüedad en la expresión "el problema de la vida", ambigizedad que aparece si por ella nos referimos a un enigma o a su solución. En el primer caso, el absurdo, la falta de sentido, amenazan la vida y la tornan problemática. En el segundo, la vida no aparece como algo problemático, pero équé significa que la vida no aparezca como algo problemático? En el caso de que esto pasara, se pregunta Wittgenstein (Observaciones, p. 56) si no habría aquí ceguera, si quien así vive no ve el más importante de los problemas. Lo que podría suceder es que para una persona tal el problema no apareciera reflejado en la duda y la insatisfacción, sino de otro modo:

O no debo decir que quien vive correctamente no experimenta el problema como tristeza, es decir, como algo problemático, sino más bien como una alegría; por así decirlo, como un ligero éter en torno a su vida y no como un trasfondo dudoso. (Observaciones, p. 56.)

Para quien vive correctamente, la vida no es problemática, el enigma está resuclto, es decir, disuelto. En un pasaje célebre del Diario filosofico (6.7.16) escribe Wittgenstein:

Y en este sentido Dostoievski tiene, sin duda, razón cuando dice que quien es feliz sarisface la finalidad de la existencia. O cabría expresarlo también señalando que satisface la finalidad de la existencia quien no necesita de finalidad alguna fuera de la vida misma. Esto es, quien está sarisfecho. La solución del problema de la vida se percibe en la desaparición de este problema.

El hombre que vive así, el hombre feliz, el hombre que ve el mundo bajo la forma de la eternidad es el que tiene la perspectiva correcta de la vida. Es 
el hombre, dice Wittgenstein, que ha aprehendido el sentido de la vida y ese sentido es la creencia en Dios. Su vida es una vida tocada por la Gracia, ha experimentado el valor absoluto. El problema de la vida para él no es problemático, no es un enigma: está resuelto, se ha desvanecido. El valor que ha aprehendido es inefable, inexpresable. En esta idea se condensa la primera, la fundamental, de las vertientes de su pensamiento ético. Es ella la que encuentra expresión en el aforismo:

Cuando algo es bueno, también es divino. Extrañamente así se resume mi ética. Sólo lo sobrenatural puede expresar lo Sobrenatural. (Observaciones, p. 16.)

Ahora quisiera decir que hay otra vertiente de este pensamiento: es la ética que, por llamarla de algún modo, llamaré etica mundana. Me parece que Wittgenstein llegó a esta concepción alternativa por una necesidad: la necesidad de seguir viviendo que tiene aquel que no ha sido tocado por la Gracia, es decir, aquel que no cree en Dios:

Cuando alguien cree haber encontrado la solución al problema de la vida y quiera decirse que ahora todo será fácil, sólo necesicará recordar para su reflexión que ha habido un tiempo en el que no se había encontrado esta "solución", pero también en ese riempo se debe de haber podido vivir, y viéndolo así, la solución encontrada parecerá una casualidad. (Obscrvaciones, pp. 17-18.)

Habíamos visto arriba que el problema de la vida podía aparecer como un enigma o como una solución. Es claro que la persona a quien se está refiriendo Wittgenstein en este pasaje es aquel para quien el problema de la vida constituye un enigma. Y él también debe poder seguir viviendo aunque su vida esté permeada por dudas y preguntas. Su existencia es cualitativamente distinta de la del hombre de fe: en la perspectiva del Diario filosofico es lo que separa al hombre feliz del hombre infeliz.

Ahora bien, ¿qué forma toma esta segunda vertiente ética y qué visión de la vida conlleva? Me parece que tres rasgos caracterizan a esta ética mundana: 1) una búsqueda incesante por dar respuesta al enigma, 2) una concepción relativa del valor y 3 ) una proyección de este valor en las circunstancias personales, dado que la ética es un problema individual.

Al igual que el creyente que está movido por la fe y orientado por ella, el hombre mundano lo está por la duda y la búsqueda de dirección. Ello requiere de una fuerza, de un ánimo. En varios pasajes subraya Wittgenstein la importancia del impulso en todas las realizaciones vitales. El religioso tiene esta fuerza, su fe es una pasión, una confianza, una dirección -ello le está dado como un don. El mundano, por el contrario, necesita encontrar en sí mismo, en lo que hace, esta fuerza. Ella es una de las características que van a confluir en la concepción de la vida valiosa en esta segunda perspectiva; 
cuando Wittgenstein se pregunte acerca de la valía de su propia existencia, uno de los parámetros centrales en esta evaluación será justamente el de la presencia o ausencia de fuerza vital en su obra. El siguiente pasaje atestigua esta idea:

Bach ha dicho que lo hizo todo sólo por aplicación. Pero tal aplicación presupone precisamente humildad y una enorme capacidad de sufrimiento, es decir, fuerza. Y quien entonces puede expresarse perfectamente, nos habla justo el lenguaje de un gran hombre. (Observaciones, pp. 126-127.)

La duda de quien no ha resuelto el problema de la vida no siempre se convierte en una fuerza que lleva a buscar la solución del enigma. Es perfectamente concebible el caso de alguien que en medio de su malestar no encuentre la fuerza para salir de él. Hay un mérito intrínseco en quien sabe traducir su malestar en un ánimo.

Otro cambio importante en el tránsito de una a otra ética lo constituye la relativización del valor. El sentido de la vida en la primera de ellas es idéntico a la aprehensión de un valor absoluto que, a su vez, es idéntico a la creencia en Dios. En la segunda, en cambio, la experiencia de un valor absoluto queda disociada de la fe religiosa. En la "Conferencia sobre ética" Wittgenstein distingue entre un sentido absoluto y un sentido relativo de las expresiones de valoración: de términos tales como "bueno", "correcto" y "deber". El sentido relativo de estos términos aparece cuando su empleo en juicios está siempre en relación con hechos, cuando siempre es posible sustituirlos por expresiones fácticas equivalentes. El lenguaje fáctico es el único lenguaje significativo. El sentido absoluto de las expresiones de valor, por el contrario, aparece en un uso analogico: estas expresiones refieren a una experiencia del valor absoluto, que no es ella misma un hecho y no puede, por consiguiente, ser expresada en el lenguaje signiî́cativo - se emplean como símiles o alegorías. Esta distinción no corresponde, sin embargo, a la que quisiera señalar aquí, pero facilita, por contraste, su presentación. La ética mundana no se ocupa del valor relativo, no pretende reducir valores a hechos. Prima facie sólo quedaría, como alternativa, que se ocupara del valor absoluto; si esto pasara, tendría que comprometerse con la fe religiosa y con los efectos que ello tiene para la vida. Sin embargo, no es claro que en la "Conferencia" Wittgenstein intente describir su propia experiencia del valor absoluto como una experiencia religiosa, a pesar de que él mismo pueda encontrar imágenes religiosas paralelas a las expresiones que usa. No toda experiencia del valor absoluto es una experiencia religiosa. Esta interpretación parece plausible si recordamos que la experiencia del valor absoluto como experiencia religiosa conlleva la disolución del problema de la vida, mientras que para Wittgenstein no es claro que tras esa experiencia el enigma haya sido resuelto. El hombre de fe encuentra en esa experiencia un testimonio de la presencia de lo divino y su vida es bañada por 
esa presencia; para el hombre mundano, en cambio, esa experiencia no tiene un efecto permanente en su vida, aparece como una vivencia intensa pero aislada, que cuando se desvanece deja un vacio, una añoranza. De este tipo sería la experiencia estética e intelectual -su objeto es inmanente, no trascendente:

Así, cuando Engelmann ve sus escritos y los encuentra maravillosos (sin embargo, no querría publicarlos individualmente) ve su vida como una obra de arte de Dios, y como tal es, desde luego, digna de admiración, cualquier vida y todo. Pero sólo el artista puede presentar lo individual de tal manera que nos parezca una obra de arte [...] Pero ahora me parece que, aparte de la tarea del artista, hay orra manera de apresar el mundo sub specic aeterni. Creo que es el camino del pensamiento que, por así decirlo, vuela sobre el mundo y lo deja tal cual es -contemplándolo desde arriba, en el vuelo. (Observaciones, pp. 18-19.)

La diferencia radical entre estos valores consiste en que la experiencia de lo divino es un don, una revelación que transforma la vida, proporciona la felicidad, acalla las dudas, mientras que la experiencia del valor inmanente proporciona un ideal o un patrón que puede orientar la construcción de una vida.

Me parece que en esta perspectiva el testimonio personal es esencial y que mucho de lo que escribe Wittgenstein acerca de ello en las Observaciones tiene justamente este carácter. Quizá fue a partir de su reflexión acerca de la civilización y la cultura, de las manifestaciones típicamente humanas —arte, religión, ciencia - y la manera en que éstas se relacionan con aquéllas, que Wittgenstein extendió su concepto de lo valioso. En la entrada del 2.9.16 de su Diario filosofico había escrito:

¿Qué me importa la historia? Mi mundo es el primero y el último.

En las Observaciones, por el contrario, encontramos muchos pasajes relativos al problema de la civilización, i. e., de la historia, de la sucesión de las culturas y el papel del individuo en ellas. En particular, Wittgenstein parece ahí obsesionado por la idea del artista creador y del genio: abundan las observaciones sobre la obra literaria y los escritores (entre ellas, una docena sobre el problema del genio de Shakespeare), sobre el lenguaje musical y los músicos, sobre la arquitectura. Y se interroga por los criterios de evaluación de las cualidades del artista, del escritor. Estas condiciones pueden ser externas (la pertenencia o no a una gran cultura, el papel del exiliado en la civilización occidental, el lugar del artista en la oposición entre civilización y cultura) o personales (el ánimo, la originalidad, la fuerza creativa, el talento, el genio). Todo ello, me parece, tiende a constituir un ideal de la persona y su carácter en el contexto más amplio de la vida social. Las siguientes conexiones pueden establecerse como bosquejo de ese ideal: el ánimo y la fuerza creativa es 
un componente necesario del genio; el genio es aquello (observable) que se expresa en una gran obra; una gran obra es el índice de una vida plenamente realizada - ello es suficiente para reconocer una vida valiosa. Se establece una analogía entre la cultura y la vida individual, entre la civilización y el entorno de esa vida, entre las obras de esa cultura y las realizaciones artísticas individuales. Las observaciones acerca de su propia obra, de su carácter de escritorpensador encajan en esta perspectiva más amplia. Si esto es así -y claramente ello sólo puede ser establecido por un estudio profundo de su pensamiento tardío-, entonces el prólogo a las Observaciones filosoficas (que se reproduce en las páginas 21 a 25 de las Observaciones) es el manifiesto de su nuevo pensamiento ético. La pertinencia de llamar "ética" a esta perspectiva de la vida humana se da porque en el encuadre de la cultura se expresa el valor humano: el único que nos es asequible si Dios no se manifiesta.

No es casual que en la caracterización de la ética mundana se tenga que recurrir siempre a una comparación con la ética absoluta; en efecto, aquélla depende en varios sentidos de ésta: el valor del que se ocupa es como un reflejo nostálgico del valor absoluto de lo sagrado, la oscuridad de sus criterios contrasta con la luminosidad y la confianza de la fe, la satisfacción que propone es pálida frente a la felicidad de quien está tocado por la Gracia:

¿Qué me inclina también a mí hacia la fe en la resurrección de Cristo? Juego, por así decir, con el pensamiento. - Si no resucitó, se pudrió en el sepulcro como cualquier hombre. Está muerto y podrido. Es pues un maestro como cualquier otro y ya no puede ayudar; estamos de nuevo desterrados y solos. Y debemos conformarnos con la sabiduría y la especulación. Estamos como en un infierno, donde sólo podemos soñar separados del cielo como por una cubierta. Pero si REALMENTE debo ser redimido necesito corteza -y no sabiduría, sueños, especulación- y esta certeza es la fe. (Observaciones, pp. 66-67.) 